Int. J. Electrochem. Sci., 14 (2019) $205-218$

International Journal of

ELECTROCHEMICAL

SCIENCE

www.electrochemsci.org

\title{
Preparation and Investigation of Nickel-Antimony co-doped Tin Oxide Anodes for Electro-catalytic Oxidation of Organic Pollutions
}

\author{
Xia $\mathrm{Li}^{1}$, Cairu Shao ${ }^{1}$, Jiangang $\mathrm{Yu}^{1}$, Kaigui $\mathrm{Zhu^{1,2,* }}$ \\ ${ }^{1}$ School of Physics and Nuclear Energy Engineering, Beijing University of Aeronautics and \\ Astronautics, 37 Xueyuan Road, Haidian District, Beijing 100191, PR China \\ ${ }^{2}$ Key Laboratory of Micro-nano Measurement-Manipulation and Physics, Ministry of Education \\ Beihang University, Beijing 100191, China \\ *E-mail: kgzhu@,buaa.edu.cn
}

doi: $10.20964 / 2019.01 .23$

Received: 5 October 2018 / Accepted: 8 November 2018 / Published: 30 November 2018

Nickel(Ni) and antimony $(\mathrm{Sb})$ co-doped $\mathrm{Ti} / \mathrm{Ni}-\mathrm{Sb}-\mathrm{SnO}_{2}$ electrodes were prepared by pyrolysis coating method and then investigated by scanning electron microscopy (SEM), X-ray diffraction (XRD), X-ray photoelectron spectroscopy (XPS), linear sweep voltammetry(LSV), electrochemical impedance spectroscopy (EIS) and accelerated service life test. We discussed the changes of oxygen evolution potential and charge transfer resistant on the Ti/Ni-Sb-SnO 2 electrodes in a physical perspective. The oxygen evolution potentials improved obviously. Furthermore, the failure mechanisms of the electrodes have been studied using the EIS and SEM techniques. Our study showed that the deactivation of Ti/Ni$\mathrm{Sb}-\mathrm{SnO}_{2}$ electrode was mainly due to the formation of a passive $\mathrm{TiO}_{2}$ passive interlayer between the $\mathrm{Ti}$ substrate and the coating.

Keywords: Titanium-based Tin oxide electrodes, DSA electrodes, Nickel, Antimony

\section{$\underline{\text { FULL TEXT }}$}

(C) 2019 The Authors. Published by ESG (www.electrochemsci.org). This article is an open access article distributed under the terms and conditions of the Creative Commons Attribution license (http://creativecommons.org/licenses/by/4.0/). 